\title{
IMPROVEMENTS IN SEISMIC PROSPECTING
}

\begin{abstract}
A GEOPHYSICAL Discussion of the Royal Astronomical Society was held at Burlington House, London, on April 20, when three papers were read on "Improvements in Seismic Prospecting". Mr. B. C. Browne (University of Cambridge) was in the chair.

The first communication, by F. W. Hales (Seismograph Service, Ltd.), dealt with the development and applications of continuous velocity logging. With the trend towards greater resolution and more detailed interpretations of seismic data, the need for a continuous record of seismic velocity against depth has become desirable. The continuous velocity logger has been developed to fulfil this requirement, and it has already demonstrated its ability to provide data on velocity and the delineation of reflecting horizons to such a degree as to make it a useful exploration tool.
\end{abstract}

The borehole instrument consists of an ultrasonic pulse generator and receiver suspended by a cable and separated from one another by a length of acoustic insulator. The pulses are radiated at a frequency of twenty per second, and both the times of transmission and reception are recorded at the surface. The time-delay, recorded continuously as a function of depth, is a direct measure of the seismic velocity in the materials forming the borehole walls. In addition, the recorder performs a mechanical integration of this velocity profile which gives the total time of travel from the surface to the depth of the instrument. In practice, the recorder-trace is calibrated by directly observing the time of travel from a surface shock by means of a pressure-sensitive detector fastened to the instrument.

It soon became apparent when using the instrument that it provided a picture of the lithology of the borehole walls as it concerns the seismologist, since the record demonstrated discontinuities in the acoustic impedance of the formations traversed. Hitherto, the geological log has provided a guide to the interpretation of seismic data, and the seismologist has naturally tried to associate reflecting surfaces with geological discontinuities. The continuous velocity logger reveals many discontinuities unsuspected by the geologist. From comparing such velocity profiles with the results of seismic reflexion shooting, the following observations have been made : (1) There are as many interfaces where there is a decrease of velocity with depth as there are where the reverse is true, and reflexions may originate at either type of interface. (2) Reflexions frequently originate from a group of thin layers with alternating strata of high and low velocity, the reflected signal being synthesized from the waves produced at each bed; this particular type of reflexion delineates a zone rather than a discrete interface. (3) Geological divisions established from palæontological considerations are frequently not characterized by any" marked discontinuity in acoustic impedance.

Difficulties in the interpretation of seismic records caused by multiple reflexion have also been resolved by the synthesis of seismic data from the continuous velocity $\log$. The details of this method of record synthesis have been given by Peterson, Fillippone and Coker'. 'They show that the reflexion coefficient may be approximately related to the incremental change in the logarithm of the acoustic impedance. If the assumption is made that the rock density and velocity are related by a simple power law, the reflexion coefficients may be determined directly from the continuous velocity log.

The derived record of acoustic impedance is used for calculating the amplitudes of reflected pulses, which are proportional to the reflexion coefficients; and after passing through shaping filters which simulate the absorption in the Earth and also through geophone and amplifier equivalent circuits, the recorded output has the nature of the seismic record which would be expected from the disposition of reflecting layers.

The log of interval velocity is more directly associated with the physics of the formation of layers rather than their chemistry, and it is therefore of great value to the geologist wishing to trace the lithology of a borehole. When used in a number of boreholes in the same district, it has often been possible to correlate the profiles from the separate holes. Unlike resistivity measurements, the measure. ments are not seriously affected by the use of highly saline drilling fluids. It has also proved possible to correlate velocity and porosity measurements within the same formation. In general, layers with low dens. ity (determined in the laboratory) have low velocities.

Work is also in progress which appears to demonstrate that when continuous velocity logging is supplemented with conventional radioactivity and electrical logs, it is possible to differentiate in some instances between the presence of gas, oil and water. In his paper, Mr. Hales showed some continuous velocity records obtained in the wells of the D'Arcy Exploration Co., Ltd., and the Compagnie d'Exploration Petrolière.

Discussing the paper, the chairman asked what ultrasonic frequency is used and whether the observed velocities are dependent on the signal frequency; Mr. P. G. Lazenby, who was joint author of the paper, said that $50 \mathrm{kc} . / \mathrm{s}$. is the pulse frequency, but no measurements have been made on the frequency dependence of velocity. Dr. T. F. Gaskell commented that measurements that have been made on coal showed no change of seismic velocity with frequency. When asked if the mud path would greatly influence the travel time, Mr. Hales said that it has been discussed, and an improved instrument is to be made having two receivers.

The second paper, read by Dr. R. Raitt, of the Scripps Institution of Oceanography, La Jolla, California, described the seismic refraction work that has been done in the equatorial Pacific Ocean on the Mid-Pacific and Capricorn Expeditions in 1950 and 1952-53, respectively. Some improvements have been made in the utilization of explosive energy for seismic waves and decreasing the noise picked up in the hydrophones. When the shot is fired at a depth corresponding to half a wave-length at the bubble pulse frequency and the hydrophones are suspended at a similar depth in a state of neutral buoyancy, the following relationship is found between the average maximum range at which signals can be observed $(\Delta$ in $\mathrm{km}$.) and the shot weight ( $W$ in lb.)

$$
\Delta=7 W^{1 / 2}
$$


There was a wide scatter from this formula; signals have been received from an $80-\mathrm{lb}$. shot at $190 \mathrm{~km}$.

In making measurements with two ships, the splitprofile type of record was most often taken; the firing ship drops charges continuously and steers an approximately straight course, passing the stationary recording ship and its hydrophones at the middle of its run. The reverse profile technique was also used occasionally; but owing to drift and navigational difficulties the full value of a reverse profile was never completely realized. For the interpretation of the seismic refraction data, the assumptions of constant-velocity layers, the velocity of which successively increased with depth, were used. In addition to the topmost layers of sediment, three distinct velocity layers were observed having velocities of $4 \cdot 0-6 \cdot 0,6 \cdot 5-7 \cdot 0$ and $8-8 \cdot 5 \mathrm{~km}$./sec., respectively. Changes in these velocities in a lateral direction were observed; but whether these are always real is uncertain. The velocity in the upper sediments was not determined by refraction; but a few reflexion measurements gave an average at $2 \cdot 15 \mathrm{~km}$. $/ \mathrm{sec}$.

Dr. Raitt presented a slide showing the thicknéss of the crust defined by the depth at which the velocity reaches $8 \mathrm{~km}$. $/ \mathrm{sec}$. as found by several workers on the continents and by his work in the Pacific Ocean. The mean thickness for the Pacific Ocean is about $6 \mathrm{~km}$., which contrasts with the $30 \mathrm{~km}$. for the continents.

Questioned on the dependence of arrival time on frequency, Dr. Raitt said that only at short distance was it possible to observe waves of different frequency travelling over the same path. In these cases, no dependence on frequency was observed. When asked by the chairman if he had any views on the com. position of the layer below the unconsolidated sediments, Dr. Raitt said that it is in doubt whether they are volcanic or sedimentary. The answer to this problem would tell us much about the history of the oceans. If the $4 \cdot 0-6 \cdot 0 \mathrm{~km}$. $/ \mathrm{sec}$. layer is lithified sediment, the oceans are probably very much older than would be expected if the layer were igneous.

Dr. S. Wyrobek (British Petroleum Co.), who read the third paper, said the refraction method has been used in some areas to give a fairly comprehensive picture of the variation of velocity in both the lateral and vertical directions and to reveal subsurface structural features. It is known that the method is most successful where velocity contrasts are pronounced, but it has been perfected to the extent of delineating layers where the velocity contrast is less than $2,000 \mathrm{ft}$./sec.

The guiding principlo in deciding the disposition of geophones and shots is to cover continuously all the important refractor's in the area and especially the shallow refractors, since these greatly infuenee the shape of the decper layers. A refraction line consists of several spreads. Each spread may have twentyfour geophones 250-1,000 ft. apart and several main shot points outside the spread at distances of 5,000 $10,000 \mathrm{ft}$. At each geophone station or every alternate one, smaller shots are fired, which elucidate the weathered layer and any low-velocity layers. Continuous time profiles are obtained in both directions of shooting, and these are used for obtaining half-intercept time values and hence the values of the refracting velocities and their lateral variations. By the method of interpretation used, individual refractors are discriminated by ensuring that the reciprocal times are equal, that the intercept times match in each direction of shooting, and that both the direct and reverse time profiles match the halfintercept time values if one deals with the same refractor.

The aim of the method is first to convert the time-distance curve into a time section, that is, into a section in which the vertical scale gives the delaytime of a point on the refractor below the datum this is achieved by producing the so-called halfintercept time profiles. From the latter, by using information obtained from well surveys or assuming the seismic velocities determined for the upper refractors to be uniform in a vertical direction, or introducing a velocity distribution characteristic of the area, a depth profile for each refractor is easily obtained.

Mr. D. R. Brown asked what velocity variations and dips could be encountered before the method broke down, to which Dr. Wyrobek replied that the complications would appear where lateral variation of velocity along a refractor approached the variation in the vertical direction. The method has proved satisfactory in areas of dips up to $8^{\circ}$. It will be published in a subsequent number of the Geophysical Prospecting Journal of the European Association of Exploration Geophysicists.

${ }^{1}$ Peterson, R. A., Fillippone, W. R., and Coker, F. B., Geophysies, 20 , No. 3, 516 (1955).

\section{ELECTRICAL EQUIPMENT OF AIRCRAFT}

$T$ HE convention, as a means of bringing to a focus widely scattered knowledge of a particular subject, has gained a great deal of popularity in recent years, and that on "Electrical Equipment of Aircraft", held in London at the Institution of Electrical Engineers during May 2-4, proved to be no exception; the accommodation of the lecture hall of the Institution was strained to the utmost, and additional chairs were placed wherever possible. The chair at the opening session was taken by the president of the Institution, Sir George $H$. Nelson, and the proceedings began with a short address by the Minister of Supply, Mr. R. Maudling.

Mr. G. R. Edwards, general manager and chief engineer (aircraft) of Vickers-Armstrongs, Ltd., followed with a most entertaining talk, in which his humorous sallies provided some light relief for the serious matter of his address, which was the problem of the aircraft designer, wishing and indeed compelled to uso electricity to an ever-increasing extent for a multitude of purposes in connexion with the functioning of the aircraft, and yet faced with the reduction of useful load-carrying ability involved in the weight and drag of electrical equipment and its cooling auxiliaries. The only electrical equipment on the earliest aircraft was a magneto generator to supply the ignition system, and this was both light and reliable. Modern large civil and military aircraft are equipped with about $150 \mathrm{~kW}$. of electrical power and, with developments likely in the near future, the power provided may rise to $400 \mathrm{~kW}$., or even, according to some estimates, to $700 \mathrm{~kW}$. The weight of the equipment, with the additional fuel required to drive it, is of the order of 3 per cent of the total aircraft weight. If the pay-load of a civil aircraft is 10 per cent of the total aircraft weight, the electrical equipment reduces the pay-load by one-quarter, and the importance of saving weight is apparent. 